\title{
GESTÃO DE GAME DESIGN: DIRETRIZES PARA A RELAÇÃO ENTRE EQUIPES NO PROCESSO DE DESIGN
}

Felipe Oviedo Frosi

Centro Universitário Ritter dos Reis - UniRitter

felipe_frosi@uniritter.edu.br

Fabiane Wolff

Centro Universitário Ritter dos Reis - UniRitter

fabiane_wolff@uniritter.edu.br

César Steffen

Centro Universitário Ritter dos Reis - UniRitter

cesar_steffen@uniritter.edu.br

Resumo: Este artigo apresenta o resultado da construção de diretrizes para o processo do design de jogos focando na interação do designer com demais profissionais. Para a construção das diretrizes são utilizados aportes teóricos de autores de Gestão de Design e, posteriormente, sobre design de jogos digitais. Como resultado são definidas e especificados apontamentos que possam orientar a estruturação de ferramentas de gestão e práticas para o processo de design de jogos, considerando a participação de diversos membros no processo, não apenas designers. Como ponto central desta construção está o papel do designer e de profissionais que atuem com o viés do design, além de se pontuar como o designer tem participação ativa no engajamento dos profissionais com as mais diversas competências e habilidades. Ao final são discutidas as diretrizes apontadas e explanados direcionamentos para sua utilização, além de apontamentos para futuras melhorias com enfoque no processo de desenvolvimento de jogos.

Palavras-chave: processo de design, gestão de design, abordagens projetuais, design de jogos.

Abstract: This paper presents the results of guidelines construction for game design process focusing on the interaction of designer with other professionals. To develop the guidelines theory of Design Management and game design are used. As results, guidelines are defined and specified, focusing in structuring management tools and practices to the game design process, considering the participation of several members, not just designers. As the central point of the construction is the designer and other professionals working with the design process, and how the designer need to active engagement of professionals with diverse skills and abilities. At 
the end guidelines are discussed and explained directions for their use as well as future improvements focusing on game development process.

Keywords: design process, design management, projective approaches, game design

\section{INTRODUÇÃO}

O design vem sendo visto como elemento estratégico por um número cada vez mais expressivo de gestores e organizações. Neste cenário é recorrente que o design se utilize de ferramentas de outras áreas do conhecimento e traga novos vieses e um novo olhar para sua inserção. Em uma realidade de mudanças cada vez mais dinâmicas e constantes, uma das indústrias que teve maior crescimento nas últimas décadas foi a indústria de jogos digitais. Por ter se tornado um expressivo setor com relevância cultural e econômica notável em diversos países, surge a necessidade de que ferramentas e processos de gestão estejam presentes, o que potencialmente pode ser melhorado com o design agregado nos processos. Relacionado a isso, a teoria de Gestão de Design pode colaborar para estruturar o design dentro do desenvolvimento de jogos digitais. Dentre os vários fatores do design de jogos que podem ser analisados e estruturados, o enfoque deste artigo está no processo de design, mais especificamente no que tange o relacionamento com outros setores e do designer com outros profissionais, além de seu posicionamento na empresa.

Este artigo tem como objetivo a análise e proposição de diretrizes que contribuam para delimitação e direcionamento do design focando o relacionamento do game designer com outros profissionais no contexto do desenvolvimento de jogos digitais. Como embasamento teórico de Gestão de Design são utilizados os trabalhos de autores como Borja de Mozota (2002) e Wolff (2010, 2012). Relacionado ao design de jogos - considerando especialmente tópicos comuns a práticas de gestão no design de jogos e a relação do designer com outros membros da equipe - são utilizados os trabalhos de Rogers (2010) e Schell (2011).

Na seção 2 é apresentada a fundamentação teórica de Gestão de Design, que definirá o processo usado como parâmetro para a construção das diretrizes e apontamentos para o design de jogos no contexto pertinente ao presente artigo. $\mathrm{Na}$ seção 3 é definida a fundamentação e contextualização do design de jogos, constituindo o segundo pilar teórico para fundamentar as diretrizes e direcionamentos propostos. Na seção 4 são analisados os dois pilares teóricos principais do trabalho: a Gestão de Design e o design de jogos. São propostas diretrizes e demais proposições de posicionamento do design de jogos perpassados pelo relacionamento do designer com outros integrantes da equipe. Por fim, na seção 5, são apresentadas as considerações finais e apontamentos para futuros trabalhos.

\section{GESTÃO DE DESIGN}

Assim como o design foi reconhecido como parte fundamental e agregador de competitividade da indústria ao longo do tempo, pode ser considerado um processo natural que o design tenha se adaptado em cenários cada vez mais complexos e dinâmicos nas organizações. 
Neste contexto, a Gestão de Design se apresenta como determinante fator para situar e direcionar o design:

\begin{abstract}
Gestão de Design é aqui definido como o uso deliberado do design como ferramenta de gestão no planejamento, produção e comercialização de bens, de modo a traduzir os objetivos estratégicos da empresa em produtos e serviços que representem diferenciais e melhorem a performance organizacional; seja ela performance de processo, produto, operacional, de materiais, da percepção do cliente, ou financeira. Dentro deste conceito, três pontos são fundamentais para a definição de como a Gestão de Design será inserida nas empresas: abordagem, integração e intenção. (WOLFF, 2012. p. 39)
\end{abstract}

A forma como a Gestão de Design será aplicada nas empresas pode ser bastante diversificada. No caso do presente artigo, no qual o desenvolvimento é focado no design de jogos, esta inserção pode ser substancialmente diferenciada de uma indústria que produz produtos físicos - se opondo a um produto digital - por exemplo.

Borja de Mozota (2002) aponta uma estreita relação entre Gestão de Design e processo de design. Segundo a autora, "mapear o processo onde o design está inserido, identificando sua inserção, integração e correlação com outras funções da empresa são etapas da própria definição teórica de Gestão de Design". Segundo Wolff (2010), o processo de design é definido como uma das três dimensões do design, divididos em processo, competência e estratégia. Na dimensão processo, o foco é definido em: método de projeto, relação entre equipes e inserção e integração do design nos processos da empresa, conforme demonstrado no quadro 1.

Quadro 1 - As três dimensões do design.

\begin{tabular}{|c|c|c|}
\hline DIMENSÕES & FOCO & NÍVEL \\
\hline Processo & $\begin{aligned} & \forall \text { Método de projeto; } \\
& \forall \text { Relação entre equipes; } \\
& \forall \text { Inserção e integração do design nos } \\
& \quad \text { processos da empresa. }\end{aligned}$ & $\begin{array}{l}\text { Estratégico e/ou Tático e/ou } \\
\text { Operacional }\end{array}$ \\
\hline Competência & $\begin{aligned} \forall & \text { Conhecimento, Habilidades e } \\
& \text { Atitudes do Designer e da equipe } \\
& \text { de design; } \\
\forall & \text { Modo de entender e fazer design. }\end{aligned}$ & Estratégico e/ou Tático \\
\hline Estratégia & $\begin{array}{l}\forall \begin{array}{l}\text { Uso do design como estratégia e } \\
\text { melhoria em diferentes níveis ou }\end{array} \\
\text { perspectivas; } \\
\forall \text { Intenção e política a empresa para } \\
\text { com o design; } \\
\forall \text { Existência de controles ou } \\
\text { indicadores para o design. }\end{array}$ & Estratégico \\
\hline
\end{tabular}

Fonte: Adaptado de Wolff, 2012

Assim como a Gestão de Design, o processo de design varia de acordo com o contexto da organização. Exemplificando esta variação, pode-se considerar que a integração entre equipes é diferente em uma mineradora e em uma empresa focada em tecnologia da informação, assim como a integração dos processos de design será 
diferenciada nestes contextos. $\mathrm{O}$ foco deste artigo está fortemente relacionado com a dimensão de processo dentro das três dimensões do design, focado em como a Gestão de Design está relacionada com este tópico. Dentro do processo, o fator principal a ser explorado é a relação entre equipes, como será aprofundado na seção 4.

$\mathrm{Na}$ indústria de jogos digitais é notório que o processo de design seja mais horizontal e orgânico que em outros contextos. Não há como não compartilhar o design com os demais profissionais, e por mais que o designer seja centralizador, os diversos profissionais com diferentes competências participarão do processo, assim como aponta Schell (2010). Apesar do design de jogos ser bastante específico, o embasamento da Gestão de Design é fundamental para compreender e melhor estruturar este processo. Sendo assim, é considerado que a perspectiva das três dimensões do design é naturalmente aplicada neste contexto, apesar das adaptações que também devem ocorrer dependendo de outras conjunturas e realidades.

\section{DESIGN DE JOGOS}

Jogos são definidos como uma atividade social do homem, tendo registros de sua existência desde tempos primitivos (HUIZINGA, 2000). Com a ascensão das tecnologias digitais, naturalmente os jogos foram inseridos neste meio. $O$ design vem sendo considerado um dos pilares mais importantes no desenvolvimento de jogos digitais. Como aponta Kent (2010), ao contrário dos primeiros jogos lançados a partir da década de 1960, o design tornou-se cada vez mais relevante para os novos títulos. Nesta época a área de jogos digitais era ainda incipiente e experimental, tendo seu foco principalmente em soluções técnicas de programação, ficando a arte visual limitada aos conhecimentos do programador e aos recursos tecnológicos disponíveis: monitores em preto e branco, equipamentos com baixa resolução e softwares gráficos primitivos. Além disto, muitos projetos partiam de iniciativas individuais ou equipe bastante reduzidas, não contando com grandes empresas capazes de propiciar espaço e estrutura adequados, tampouco com tecnologias que possibilitassem produções de alta qualidade por tais equipes. Neste cenário com poucos recursos e dominado pelo empirismo nos projetos, havia pouca ou nenhuma possibilidade para aplicações de metodologias de design.

A ascensão do design e o reconhecimento de sua relevância no desenvolvimento de projetos (BÜRDEK, 2006; BONSIEPE, 2011) também teve influência na indústria de jogos, impulsionando-a como uma das mídias de entretenimento mais relevantes da atualidade no ponto de vista econômico, social e cultural. O design de jogos coloca o jogador (usuário) como um dos principais elementos no processo de desenvolvimento. Apesar de não ignorar aspectos tecnológicos, o enfoque no design de jogos é, acima de tudo, criar uma experiência focada no jogador (KOSTER, 2004; SCHELL, 2011).

O crescimento da indústria de jogos foi acompanhado pelo desenvolvimento tecnológico, no qual diversas ferramentas surgiram. Dentre as tecnologias mais relevantes estão as game engines (motores de jogos), que podem ser definidas como as bases tecnológicas em que os jogos serão construídos. Traçando um comparativo superficial, as engines são como plataformas de um carro, onde a carroceria - aspectos visuais - são alterados, mas o funcionamento mecânico permanece com seu núcleo inalterado. Através destas tecnologias os desenvolvedores gerenciam efeitos sonoros, elementos visuais (como imagens de interfaces gráficas, modelos 3D e animações), e a 
programação. A game engine é a centralizadora dos elementos de um jogo, pois é através dela que diferentes profissionais com diferentes competências farão a junção de todos os elementos desenvolvidos (sejam visuais, sonoros ou lógicos/funcionais), para que operem de forma integrada e harmoniosa.

Além de tecnologias como as game engines, os profissionais atuantes na indústria ficaram cada vez mais especialistas em uma área específica: atualmente é comum que um profissional se foque somente em modelagem 3D, ou ainda em algo mais específico, como a modelagem de uma determinada parte do corpo humano. Outras atividades apresentaram esta mesma necessidade, como a programação ou desenvolvimento de efeitos sonoros e trilhas sonoras. Dentre todas as competências citadas e necessárias para a construção de um jogo digital, que envolvem múltiplas habilidades e tecnologias, o design apresenta a necessidade de estar integrado com diversas áreas que não dizem respeito somente ao desenvolvimento do produto, sendo assim, neste contexto, busca-se situar como o designer deve atuar em conjunto com profissionais das mais diversas competências. Esta inserção será discutida pontualmente na próxima seção.

\section{GESTÃO DE GAME DESIGN: O PROCESSO DE DESIGN DE JOGOS}

Os processos de gestão e design podem passar por adaptações de acordo com a organização em que são inseridos. De acordo com o contexto, essas adaptações são mais evidentes. Considerando a realidade do desenvolvimento de software, apesar destas variações existirem, são apresentadas diversas ferramentas de gestão consolidadas e que atendem um amplo conjunto de necessidades das empresas. Para o desenvolvimento de jogos digitais, não existe um modelo consolidado, ou como aponta Schell (2011), "não existe modelo mágico". Não é simples analisar o motivo de uma falta de padronização tão forte na indústria de jogos. Uma possível análise é considerar a realidade de um sistema computacional de gestão comparado a um jogo digital. Um sistema de gestão, por mais que possa ter um enfoque em diferentes contextos, possui certa semelhança na forma de entrada e saída de dados, em como devem ser projetados controles como: estoque, colaboradores, matérias-primas, entre outros. Em um game isso é totalmente diferente. Cada jogo é substancialmente diferenciado dos demais e com aspectos únicos, no qual devem ser projetadas características que simulem um mundo inteiro. Por mais que este mundo seja mais simples que o mundo real, ele não deixa de ser um mundo, pois possui um espaço, regras de física, habitantes (personagens), em muitos casos uma topografia, cidades, veículos e ambientações próprias.

O design de jogos é um processo orgânico e com uma grande variação de acordo com o projeto (SCHELL, 2011). O desenvolvimento de jogos digitais - em sua maior parte -atende a indústria de jogos, focando em um mercado consumidor abrangente e potencialmente rentável, ou seja, atende um negócio que busca retorno financeiro para a empresa, tendo o design como um de seus alicerces. Para que isso ocorra a Gestão de Design é necessária e, ao mesmo tempo, algo desafiador a se inserir.

Schell (2011) aponta que para se criar um jogo é necessária uma equipe diversificada e com diferentes habilidades artísticas e técnicas. O autor ainda aponta que o fator principal entre todos os membros da equipe de desenvolvimento é que se tenha um forte engajamento e prazer com o produto em que se está trabalhando, o 
que é definido praticamente como uma relação de amor. Este é o ponto principal, segundo autor, e algo que se torna bastante desafiador de ser gerido. Para evitar que este fator seja negligenciado, são apontados três tipos básicos de problemas a serem analisados:

- Problema 1: Membros da equipe incapazes de amar qualquer jogo - muitas pessoas entram no negócio de jogos por ser um negócio, não por amarem o que fazem e trabalhar com isso. Estas pessoas devem ser evitadas.

- Problema 2: Membros da equipe apaixonados por um jogo diferente dos que estão criando - em alguns casos os membros da equipe podem amar jogos, mas podem não amar o jogo em que estão trabalhando e preferir trabalhar com gêneros diferentes. O designer pode contribuir direcionando a atuação dos demais membros e fazendo com que, vendo o trabalho com outros vieses, fiquem engajados no processo.

- Problema 3: Os membros da equipe apaixonados por diferentes visões do mesmo jogo - Este problema é bastante recorrente. Os membros da equipe estão entusiasmados com o trabalho e apaixonados pelo desenvolvimento do projeto, contudo, não estão apaixonados por exatamente a mesma coisa, pois possuem visões diferentes do jogo. Neste caso, o designer deve contribuir com delimitações e com uma clara mensagem das principais características do jogo.

O designer pode e deve contribuir para que os demais membros da equipe estejam engajados e motivados com o projeto, contudo, não se pode ignorar que o designer é um ser humano que apresenta fraquezas e limitações, portanto também pode não estar apaixonado pelo título. A partir daí pode-se definir um quarto problema:

- Problema 4: O designer não está apaixonado pelo título: considerando a importância do designer no processo de desenvolvimento de um jogo digital, este pode ser um grande problema. Contudo, existe uma diferença em amar o jogo e amar o seu trabalho. Uma possível solução é encontrar uma motivação, mesmo que não seja o jogo em si. Se não é possível amar o jogo, o designer deve ver além e amar seu público, procurando preparar o jogo como se fosse um presente para aqueles que irão utilizá-lo, mesmo que essa preparação não seja tão prazerosa quanto se gostaria.

O que foi descrito até agora nesta seção pode ser interpretado com o que Wolff (2010, 2012) classificou como a segunda dimensão do design: Competência, pois muito se falou de conhecimento, habilidades e atitudes do designer de jogos, e esta leitura não está equivocada. Contudo, esta análise é feita para construir direcionamentos para o processo de design, o que necessariamente não pode ignorar elementos da segunda dimensão.

Se todos os membros da equipe estiverem engajados no processo, motivados e se sentindo parte importante no projeto, este é um cenário que tem potencial para gerar um produto final adequado. Contribuir para a construção deste cenário é dever do designer. Apesar disso, este cenário leva a um outro problema, que apesar de não envolver a falta de motivação, pode ser considerado o problema 5: 
- Problema 5: Todos os membros da equipe têm opiniões sobre o design do jogo toda a equipe terá opiniões sobre o design e isso deve ser um fator a ser gerido pelo designer. Uma boa gestão das opiniões recebidas tende a fortalecer o design do jogo, tornando-o mais sólido e compreensível para todos.

O design do jogo não é feito somente pelo designer. Todos ou quase todos os membros da equipe de desenvolvimento terão participação no processo, ainda que pequena. Para que isso ocorra de forma eficiente, a comunicação da equipe deve ser feita de forma correta. Para isso, Schell (2011) aponta nove pontos a serem seguidos:

- Objetividade: comunicar-se com objetividade sem se prender a ideias pessoais, tentando atender à coletividade para o melhor desenvolvimento do projeto.

- Clareza: Falar de forma clara para que todos compreendem o que foi dito. Se algum membro da equipe falar algo que não ficou claro, não ignorar.

- Persistência: O que é apenas verbalizado pode ser facilmente esquecido, portanto registrar de forma escrita (física ou digital) é importante.

- Conforto: Um local confortável fomenta uma boa comunicação e surgimento de ideias.

- Respeito: Ouvir é uma das habilidades principais de um bom designer de jogos. Ouvir os demais membros da equipe é um sinal de respeito.

- Confiança: É importante para o designer e para a equipe ter confiança mútua, neste ponto encontros presenciais são muito importantes no processo, sendo que os encontros devem ter certa frequência.

- Honestidade: A falta de honestidade pode quebrar a confiança e por consequência a comunicação. Um bom designer deve ser honesto com os demais membros do grupo.

- Privacidade: Algumas opiniões dificilmente serão expressas em fóruns públicos ou em um grande grupo. É papel do designer conversar de forma privada e face a face com os membros da equipe.

- Unidade: Mesmo que algum membro seja teimoso e se apegue a ideias que o grupo tem conviç̧ão que não são o melhor caminho para o projeto, o designer deve compreender as motivações daquele membro e engajar todos para entrar em consenso sobre as decisões e buscar unidade.

Cada estúdio de desenvolvimento de jogos terá diferentes formas de aplicar esses pontos, contudo, eles tendem a contribuir com o processo de design de jogos, mesmo em diferentes contextos. Apesar do apontamento que leva a contribuição de diversos profissionais que influenciem o design, é preferível que existam alguns membros chave que participem do processo e reuniões de design. Ao definir o processo em si, uma das ferramentas recorrentes usadas é o brainstorming.

Antes de iniciar um brainstorming, é preciso definir algumas regras. Primeiramente, não existem ideias estúpidas. Diga sim para tudo nesta etapa. Esteja certo que você estará com pessoas com outras competências além do game design: programadores, artistas, testadores, roteiristas. Quanto mais diverso for seu grupo, melhor. As pessoas sempre me surpreendem com o que trazem para o processo de criação. (ROGERS, 2010. p. 32) 
O processo de participação dos demais membros da equipe é definido por Schell (2011) em quatro etapas:

1. Brainstorming inicial: Envolve o maior número possível de membros da equipe.

2. Design independente: Membros da equipe básica de design pensando em ideias de maneira independente.

3. Discussão sobre o design: Membros de equipe básica de design compartilham suas ideias independentes para discutir e tentar chegar a um consenso sobre essas ideias.

4. Apresentação do design: Os membros da equipe básica de design apresentam seu progresso para toda a equipe, dando tempo para comentários e críticas. Isso pode se transformar em brainstorming, o que retorna ao item 1 e inicia um ciclo.

A comunicação ocorrendo de forma correta é essencial para que este ciclo seja virtuoso, em especial quando as definições de design são apresentadas aos membros da equipe que não participaram de todas as etapas de forma ativa. A partir destes apontamentos, é proposta uma especificidade que procura aprofundar uma das dimensões do design - o processo - (WOLFF, 2012) a ser aplicada no contexto do desenvolvimento de jogos digitais, conforma apresenta o quadro 2:

Quadro 2 -Diretrizes para a atuação entre equipes no design de jogos considerando a dimensão Processo.

\begin{tabular}{|l|l|}
\hline ÂMBITO & DIRETRIZES \\
\hline Problema x Ação & $\begin{array}{l}\text { Membros incapazes de amar o jogo - evitar membros da } \\
\text { equipe com estas características; } \\
\text { Membros da equipe apaixonados por outro jogo - fomentar } \\
\text { fatores motivacionais da equipe; } \\
\text { Membros da equipe com diferentes visões sobre o jogo - } \\
\text { delimitar e especificar as definições de design com a } \\
\text { participação da equipe; } \\
\text { Designer não apaixonado pelo jogo - encontrar outra } \\
\text { motivação, como o público; } \\
\text { Opinião de toda equipe sobre design - engajar e filtrar } \\
\text { opiniões para consolidar o design. }\end{array}$ \\
\hline Cojetividade; Clareza; Persistência; Conforto; Respeito; \\
Confiança; Honestidade; Privacidade; Unidade. \\
\hline Etapas do processo & $\begin{array}{l}\text { Brainstorming inicial - diversos membros da equipe; } \\
\text { Design independente - equipe básica de design; } \\
\text { Discussão sobre o design - equipe básica de design; } \\
\text { Apresentação do design - equipe básica de design para toda } \\
\text { a equipe, reiniciando ciclo. }\end{array}$ \\
\hline
\end{tabular}

Fonte: Desenvolvido pelo autor

Estas diretrizes não têm como objetivo fornecer um modelo de gestão absoluto para qualquer estúdio que queira adotá-lo. Assim como não existem documentações e 
processos absolutos no desenvolvimento de jogos, as ferramentas de gestão também necessitam ser adaptadas ao contexto específico, e isso não remete somente a um estúdio, mas sim a cada diferente projeto que este estúdio estará desenvolvendo.

\section{CONCLUSÃO}

Este artigo apresentou os resultados da proposição de diretrizes que contribuam para a Gestão de Design no processo de desenvolvimento de jogos digitais, focando a interação e relação dos designers de jogos com demais profissionais. Foram analisados os trabalhos de autores de Gestão de Design como Borja de Mozota (2002) e Wolff $(2010,2012)$, no qual se utilizou como base teórica principal as três dimensões do design. Relacionado ao design de jogos o aporte teórico principal ocorreu pelos trabalhos de Rogers (2010) e Schell (2011).

O resultado da proposição foi a construção de um quadro teórico onde são delimitados três âmbitos: Problema x Ação, Comunicação e Etapas do processo. Para cada âmbito foram definidas diretrizes que podem colaborar com a Gestão de Design no desenvolvimento de jogos digitais, considerando a necessidade de adaptação das ferramentas de gestão para a realidade de cada projeto de jogo.

O processo de design de jogos é complexo e requer uma ampla combinação de competências, habilidades e atitudes de diversos profissionais para ser concretizado com qualidade. Este artigo propôs um apontamento que pode contribuir para organizar este processo em um âmbito específico: a interação entre equipes dentro do processo de design. Levando em conta uma maior abrangência, as três dimensões poderiam gerar outras diretrizes e apontamentos mais completos e complexos. Espera-se que trabalhos futuros possam contribuir para abranger as demais dimensões do design e contribuir com a Gestão de Design para o desenvolvimento de jogos digitais.

\section{REFERÊNCIAS}

BONSIEPE, Gui. Design, Cultura e Sociedade. São Paulo, Edgard Blucher, 2011.

BORJA DE MOZOTA, Brigitte. Design and Competitive Edge: A model for design management excellence in European SMEs. Design Management Journal, 2002.

BÜRDEK, Bernhard. História, Teoria e prática do Design de Produtos. São Paulo: Edgard Blucher, 2006.

HUIZINGA, Johan. Homo Ludens: o jogo como elemento da cultura. São Paulo: Perspectiva, 2000.

KENT, S. The Ultimate History of Video Games: from Pong to Pokemon and beyond... the story behind the craze that touched our lives and changed the world. Crown Publishing Group, 2010.

KOSTER, Raph. A Theory of Fun for Game Design. Phoenix: Paraglyph Press, 2004.

ROGERS, Scott. Level Up: The Guide to Great Video Game Design. Chichester: John Wiley \& Sons, 2010.

SHELL, Jesse. The Art of Game Design: A Book of Lenses. Rio de Janeiro: Elsevier , 2011. 
WOLFF, Fabiane. Sistemática de Avaliação da Gestão de Design. Tese de Doutorado. Programa de Pós-Graduação em Engenharia de Produção. Universidade Federal do Rio Grande do Sul. 2010.

WOLFF, Fabiane. Gestão de Design: Modelo Conceitual e Sistemática de Avaliação. Porto Alegre: Editora UniRitter, 2012. 